\title{
Editorial Teams of the English Edition
}

\begin{tabular}{|c|c|}
\hline Editor & $\begin{array}{l}\text { Li Yuming (李宇明) } \\
\text { Beijing Language and Culture University } \\
\text { liyum@263.net }\end{array}$ \\
\hline English Editor & $\begin{array}{l}\text { Li Wei (李嵬) } \\
\text { University College London } \\
\text { li.wei@ucl.ac.uk }\end{array}$ \\
\hline Associate Editors & $\begin{array}{l}\text { Guo Xi (郭熙) } \\
\text { Jinan University } \\
\text { guoxi91@126.com } \\
\text { Zhou Hongbo (周洪波) } \\
\text { The Commercial Press } \\
\text { zhouhongbo@cp.com.cn } \\
\text { Zhou Qingsheng (周庆生) } \\
\text { Chinese Academy of Social Sciences } \\
\text { zhouqs@cass.org.cn }\end{array}$ \\
\hline Editorial Assistants & $\begin{array}{l}\text { Xu Xiaoying (许小颖) } \\
\text { Beijing Normal University } \\
\text { xuxiaoying2000@bnu.edu.cn } \\
\text { Dai Wenying (戴文颖) } \\
\text { The Commercial Press } \\
\text { daiwenying@cp.com.cn }\end{array}$ \\
\hline Translation & $\begin{array}{l}\text { Fletcher Translations, Inc. } \\
\text { Contact person: Carissa Fletcher } \\
\text { cfletcher205@gmail.com }\end{array}$ \\
\hline
\end{tabular}


